\title{
Regulation by sucrose of storage compounds breakdown in germinating seeds of yellow lupine (Lupinus luteus L.), white lupine (Lupinus albus L.) and Andean lupine (Lupinus mutabilis Sweet). II. Mobilization of storage lipid
}

\author{
Sławomir Borek • Stanisława Pukacka • \\ Krzysztof Michalski
}

Received: 9 June 2011/Revised: 12 October 2011/Accepted: 6 December 2011/Published online: 18 December 2011 (C) The Author(s) 2011. This article is published with open access at Springerlink.com

\begin{abstract}
Research of the regulatory function of sucrose in storage lipid breakdown was conducted on isolated embryo axes, excised cotyledons and whole seedlings of three lupine species grown in vitro on medium with $60 \mathrm{mM}$ sucrose or without the sugar. Lack of sucrose in the medium caused significant increase in total lipid content in yellow, white and Andean lupine isolated embryo axes but in Andean lupine seedling cotyledons and excised cotyledons, lipid level was clearly lower in carbohydrates deficient conditions. Sucrose caused no significant effect on fatty acids spectra. The main fatty acid in yellow lupine seeds was linoleic acid, in white lupine oleic acid and in Andean lupine both oleic and linoleic acids. The main phospholipid in organs of three lupine species was phosphatidylcholine. In sugar-deficient conditions, content of phosphatidylcholine and some others phospholipids was decreased. The peculiar features of regulation by sugars of storage lipid breakdown in germinating lupine seeds and induction of autophagy in young carbohydrate starved embryo axes is discussed.
\end{abstract}

Keywords Autophagy · Fatty acid - Legume · Phospholipid · Sugar starvation

Communicated by S. Weidner.

S. Borek $(\bowtie)$

Department of Plant Physiology, Adam Mickiewicz University, ul. Umultowska 89, 61-614 Poznan, Poland

e-mail: borek@amu.edu.pl

\section{S. Pukacka}

Institute of Dendrology, Polish Academy of Sciences, ul. Parkowa 5, 62-035 Kórnik, Poland

K. Michalski

Plant Breeding and Acclimatization Institute,

ul. Strzeszyńska 36, 60-479 Poznan, Poland

\section{Introduction}

In mature lupine seeds, the main storage compound is protein, mainly globulins (Ratajczak et al. 1999; Duranti et al. 2008). In yellow lupine seeds, protein content may reach about $45 \%$ of dry matter (Cerletti 1982), in white lupine seeds up to 38\% (Mohamed and Rayas-Duarte 1995) and in Andean lupine seeds 40-50\% (Santos et al. 1997). Lupine seeds contain large quantities of storage lipid as well. In yellow lupine, lipid content is about $6 \%$ of dry matter, in white lupine seeds $7-14 \%$ and in Andean lupine seeds up to $20 \%$ (Borek et al. 2009). In this case, Andean lupine seeds are similar to soybean seeds, which may contain 12-26\% of storage lipid (Zhou et al. 2006). Carbohydrate content in lupine seeds is on average about $36.5 \%$ of dry matter, of which $26 \%$ is fiber (Hedley 2001). Lupine seeds contain no starch (Borek et al. 2006, 2011a; Duranti et al. 2008).

Investigations concerning storage lipid breakdown in germinating lupine seeds have been conducted nearly exclusively on yellow lupine seeds, i.e. the species that accumulate small amount of lipid in seeds. It has been shown that in yellow lupine seeds, oil bodies are located mainly in cotyledons, but quite numerous oil bodied are present in embryo axes as well. During germination storage lipid is quickly mobilized and almost all bodies in embryo axes disappear after four days of germination (Borek et al. 2006, 2011a). In germinating yellow lupine seeds, strong connections between pathways of storage lipid breakdown and pathways of amino acids synthesis have been detected. Storage lipid is used as respiratory substrate or is converted into sugars, but some part of lipid derived carbon skeletons is used for amino acids synthesis (mainly asparagine, glutamine and glutamate) (Borek et al. 2003; Borek and Ratajczak 2010). Moreover, when asparagine synthesis is 
disrupted (by L-methionine sulfoximine-an inhibitor of glutamine synthetase), changes in lipid breakdown are observed. In yellow and white lupine embryo axes and cotyledons, a slight increase in lipid utilization has been detected, but in Andean lupine embryo axes and cotyledons, L-methionine sulfoximine causes significant enhancement in lipid utilization (Borek et al. 2011a). In a research of carbon flow from storage lipid into amino acids (as well as into sugars), the radiolabelled acetate as the simplest fatty acid was used (Borek et al. 2003; Borek and Ratajczak 2010).

In research of regulation of storage lipid breakdown, sucrose is taken under consideration. This sugar is very important because of storage lipid is synthesized from sucrose in developing seeds (Weber et al. 2005; Baud et al. 2008) and sucrose is one of the main end products of storage lipid degradation in germinating seeds (Graham 2008; Quettier and Eastmond 2009). Otherwise, sucrose and glucose are important signaling molecules in plant metabolism regulatory network and these sugars might control plant cell metabolism by modification of expression of many genes (Smeekens et al. 2010). Experiments regarding regulatory function of sucrose in lipid metabolism in lupine seeds are not numerous and have been conducted almost only on yellow lupine seeds. Ultrastructure investigations have showed that oil bodies in cotyledons and in embryo axes are smaller, less numerous or disappeared when sugars level decreases in tissues (Borek et al. 2006, 2011a). Lipase and catalase activity increases in sugar-depleted conditions (Borek et al. 2006), but enzymes involved in further steps of lipid breakdown (cytosolic aconitase, isocitrate lyase, $\mathrm{NADP}^{+}$-dependent cytosolic isocitrate dehydrogenase) are more active in sucrose-fed tissues (Borek and Nuc 2011). Moreover, it has been proved that increase or decrease of enzyme activity is caused by modification of gene expression. Lipase mRNA level is higher and mRNA levels for cytosolic aconitase and $\mathrm{NADP}^{+}$-dependent isocitrate dehydrogenase are lower in yellow lupine cotyledons and embryo axes in which sugars content is decreased (Borek and Nuc 2011). Cytosolic aconitase and $\mathrm{NADP}^{+}$-dependent isocitrate dehydrogenase are important enzymes in the above-mentioned pathways of carbon flow from storage lipid into amino acids in germinating seeds of yellow lupine (Borek et al. 2003, 2011a; Borek and Ratajczak 2010). Stimulatory effect of sucrose on these two enzymes activity is correlated with the enhanced carbon flow from lipid to amino acids, because amino acids synthesis from lipid derived carbon skeletons is significantly higher in sucrose-fed embryo axes and cotyledons (Borek and Ratajczak 2010).

Since lupine seeds contain large protein quantities, they have been used mostly in research concerning storage protein and amino acids metabolism. Experiments regarding storage lipid metabolism in lupine seeds are not numerous, so data presented in this paper enlarge our knowledge about storage lipid breakdown during germination and its regulation by sucrose. This work is the continuation of described above research conducted on germinating yellow lupine seeds and the next elements of storage lipid breakdown were investigated in this species. However, the very important aim of the research was checking how sucrose regulates lipid breakdown in lupine seeds, which accumulate much more this storage compound than yellow lupine seeds. Since investigations were conducted on seeds of three lupine species, i.e. yellow lupine (lipid content about $6 \%$ of dry matter), white lupine (7-14\%) and Andean lupine (about 20\%), to define the regulatory function of sucrose, the isolated embryo axes, excised cotyledons and seedlings were grown in vitro on medium with $60 \mathrm{mM}$ sucrose or without the sugar. Sucrose in this concentration added to the medium caused significant increase in soluble carbohydrate and starch levels in growing in vitro lupine embryo axes, cotyledons and seedlings. Lack of sucrose in the medium caused considerable decrease in soluble carbohydrate and starch content in tissues, especially in isolated embryo axes (Borek et al. 2006). In this paper, the total lipid level, fatty acids spectrum, and phospholipids content are presented.

\section{Materials and methods}

\section{Plant material}

Yellow, white and Andean lupine seeds were surfacesterilized in $0.02 \% \mathrm{HgCl}_{2}$ for 10,15 and $20 \mathrm{~min}$, respectively, and allowed in the dark to imbibe for $24 \mathrm{~h}$ at $25^{\circ} \mathrm{C}$. Embryo axes and cotyledons isolated from imbibed seeds, as well as whole imbibed seeds deprived of their coats, were placed on sterilized filter paper (Whatman no. 3) in sterile tubes above Heller's medium (Heller 1954) in two trophic variants: with $60 \mathrm{mM}$ sucrose $(+S)$ and without sucrose $(-S)$. Isolated embryo axes, excised cotyledons and seedlings were cultured in vitro for $96 \mathrm{~h}$ in the dark at $25^{\circ} \mathrm{C}$. All experiments were conducted on isolated organs as well as on seedling organs because it enabled to detect undesirable effect of injury, i.e. isolation of organs.

\section{Total lipid determination}

Total lipids were extracted from embryo axes and cotyledons of air dry and imbibed ( $24 \mathrm{~h})$ yellow, white and Andean lupine seeds as well as from organs grown in vitro for $96 \mathrm{~h}$ using chloroform:methanol $(2: 1, \mathrm{v} / \mathrm{v})$ containing $0.05 \%$ butylated hydroxytoluene (BHT), according to Allen et al. (1966), as described by Pukacka (1991). The amounts of lipid were determined gravimetrically. 
Fatty acids determination

Spectrum of total fatty acids were determined in embryo axes and cotyledons of air dry and imbibed $(24 \mathrm{~h})$ yellow, white and Andean lupine seeds as well as in organs grown in vitro for $96 \mathrm{~h}$ according to Borek et al. (2009). Fatty acids (as methyl esters, after transmethylation of the extracted lipids with $500 \mathrm{mM} \mathrm{KOH}$ in methanol for $15 \mathrm{~min}$ at $70^{\circ} \mathrm{C}$ and extracted in hexane) were determined by using an Agilent 6890 gas chromatograph, column 30 m DB25, temperature $200^{\circ} \mathrm{C}$, and a flame ionization detector (FID).

\section{Phospholipids determination}

Phospholipids were determined in aliquots of the lipid extracts (describes above) separated by one-dimensional TLC in chloroform:methanol:acetic acid:water (85:15: 10:3.5, v/v; Nichols et al. 1965), using original phospholipid standards. Spots containing phospholipids and detected with iodine vapor were scraped off for analysis of phosphorus. The phosphorus content was estimated according to Ames (1966).

\section{Statistical analysis}

The results are the mean $\pm \mathrm{SD}$ of three independent experiments with two or three replications each. Significance of differences between mean values was determined with Student's $t$ test. The statistical analysis were connected only to assessing the significance in the differences between organs grown in vitro on medium containing $60 \mathrm{mM}$ sucrose $(+\mathrm{S})$ and organs grown on medium without sucrose $(-\mathrm{S})$.

\section{Results}

In mature lupine seeds, storage lipid was accumulated both in cotyledons and in embryo axes. In yellow lupine seeds, which contain only about $6 \%$ of lipid in dry matter, the lipid level was almost the same in embryo axes and in cotyledons, but in white lupine seeds (lipid content 7-14\%) and Andean lupine seeds (lipid content about 20\%), cotyledons contained more lipid than embryo axes (Fig. 1; dry seeds). After $24 \mathrm{~h}$ of imbibition, the total lipid content in axes and cotyledons was considerably lower than in dry seeds axes and cotyledons (Fig. 1), but it is rather obvious result because of watering of tissues. Apart from the in vitro culture conditions, a huge decrease (comparing to axes and cotyledons of imbibed seeds) in total lipid content was observed in 96-h seedling axes of yellow, white and Andean lupine. Similar decrease was noted in yellow and Andean lupine seedling cotyledons. In in vitro grown isolated embryo axes and excised cotyledons, the decrease in total lipid level was smaller than in seedling organs. The clearest examples for this were yellow lupine excised cotyledons or Andean lupine isolated embryo axes (Fig. 1). Sucrose added to the medium $(+S)$ caused no significant changes in total lipid level in yellow, white and Andean lupine seedling axes. Distinct differences in total lipid content were visible in isolated embryo axes. Lipid level was significantly higher in white and Andean lupine sucrose starved $(-S)$ isolated embryo axes than in fed with sucrose $(+\mathrm{S})$ ones (Fig. 1). The differences were even more pronounced when the total
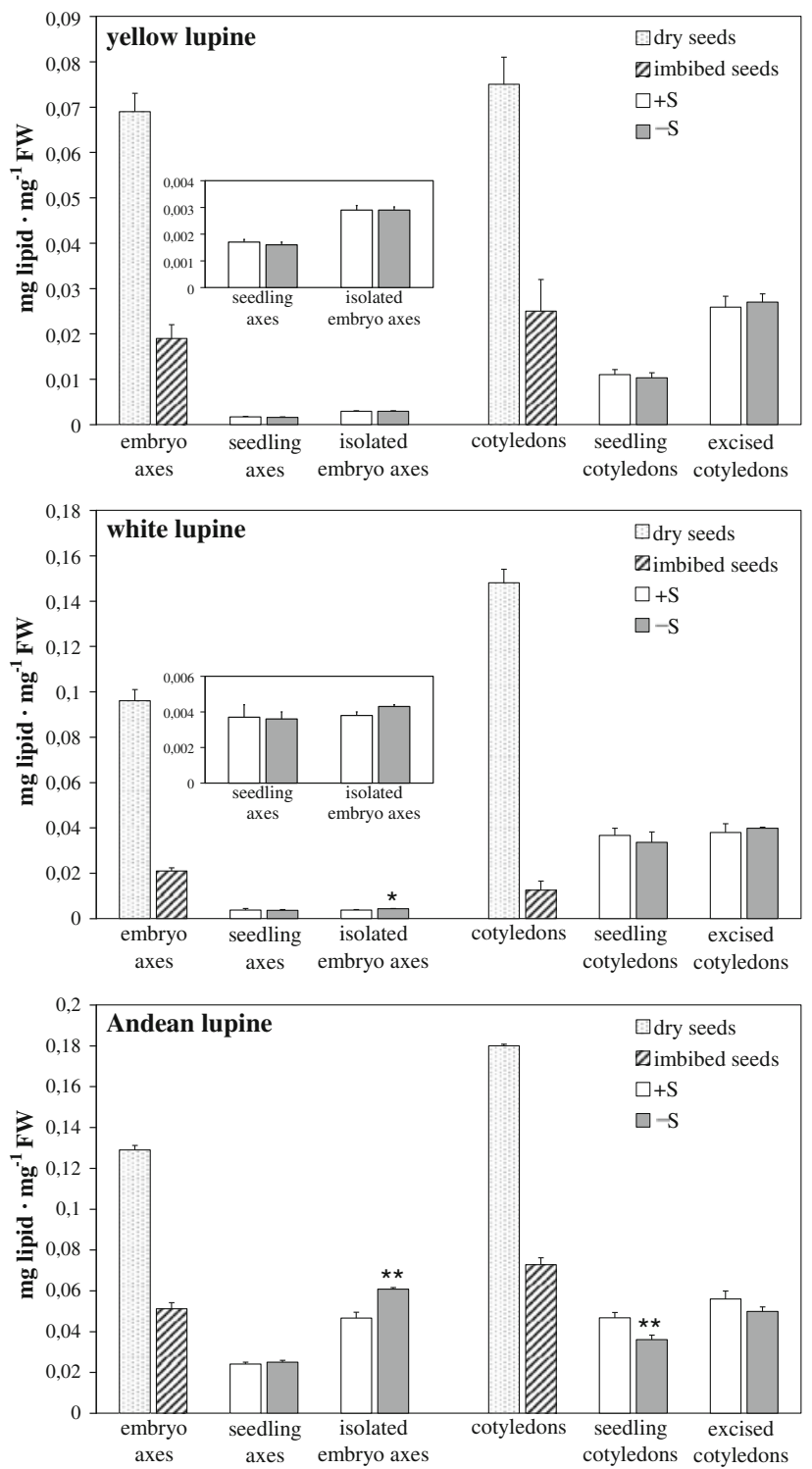

Fig. 1 Total lipid content in yellow, white and Andean lupine embryo axes and cotyledons of dry and imbibed $(24 \mathrm{~h})$ seeds and in organs grown in vitro for $96 \mathrm{~h}$ on medium with $60 \mathrm{mM}$ sucrose $(+\mathrm{S})$ or without the sugar $(-\mathrm{S})$. Small graphs are the magnification of total lipid content in seedling axes and isolated embryo axes. Statistical significance at $P \leq 0.05(*)$ or at $P \leq 0.01(* *)$ 
lipid content was calculated on axes dry matter. Then the lipid content was considerably higher in sucrose starved $(-S)$ yellow, white and Andean lupine isolated embryo axes (higher lipid level by 43,44 and $70 \%$, respectively). In grown in vitro yellow and white lupine cotyledons (both seedling and excised cotyledons), lipid level was similar in $+\mathrm{S}$ and $-\mathrm{S}$ organs and differences were not statistically significant. Only in Andean lupine cotyledons the lipid level was lower in sugars depletion conditions $(-S)$ in tissues and the difference in seedling cotyledons was highly statistically significant (Fig. 1).

In embryo axes and cotyledons of yellow lupine dry and imbibed seeds, the prevailing fatty acid was linoleic acid (Fig. 2a); in white lupine seeds, it was oleic acid (Fig. 3a), and in Andean lupine seeds, it was oleic and linoleic acids (Fig. 4a). During $24 \mathrm{~h}$ of imbibition in embryo axes and cotyledons of all three lupine species, no changes in fatty acid spectra were detected (Figs. 2a, 3a, 4a). However, during $96 \mathrm{~h}$ of growth, clear changes were observed in seedling axes and isolated embryo axes comparing to fatty acids spectra in axes of dry and imbibed seeds. In yellow lupine seedling axes, linoleic acid decreased and the main fatty acid was linolenic acid (Fig. 2b). In isolated embryo axes, the prevailing fatty acid was still linoleic acid, but percentage of linolenic acid increased (Fig. 2b). In white lupine seedling axes, oleic acid decreased, whereas linolenic acid increased (Fig. 3b). In isolated embryo axes, oleic acid decreased and the prevailing fatty acid was linoleic acid (Fig. 3b). In Andean lupine seedling axes and isolated embryo axes, a clear decrease in oleic acid was observed and the main fatty acid was linoleic acid (Fig. 4b). Contrary to above described changes occurring in axes, no such clear changes were observed in grown in vitro yellow, white and Andean lupine cotyledons (Figs. 2c, 3c, 4c). Taking under account the trophic conditions of in vitro culture, it can be concluded that sucrose caused no many significant changes in fatty acids spectra. These changes were detected mainly in yellow and white lupine axes and cotyledons and were connected mainly with fatty acids which content in tissues was low, for example palmitooleic acid, eicosenoic acid or erucic acid (Figs. 2b, c, 3b, c, 4b, c). Only one change was connected with the prevailing fatty acid, namely, the percentage of linoleic acid was lower in cotyledons of yellow lupine seedlings grown on medium without sucrose (-S; Fig. 2c).

In embryo axes and cotyledons of dry and imbibed seeds as well as in organs grown in vitro of each of the three lupine species, the main phospholipid was phosphatidylcholine (Figs. 5a-c, 6a-c, 7a-c). Similarly to total lipid level (Fig. 1), a huge decrease in the content of each phospholipid was detected during 24-h imbibition (Figs. 5a, 6a, 7a). Additional decrease in phospholipids content was observed after $96 \mathrm{~h}$ of growth (Figs. 5b, c, 6b, c, 7b, c).
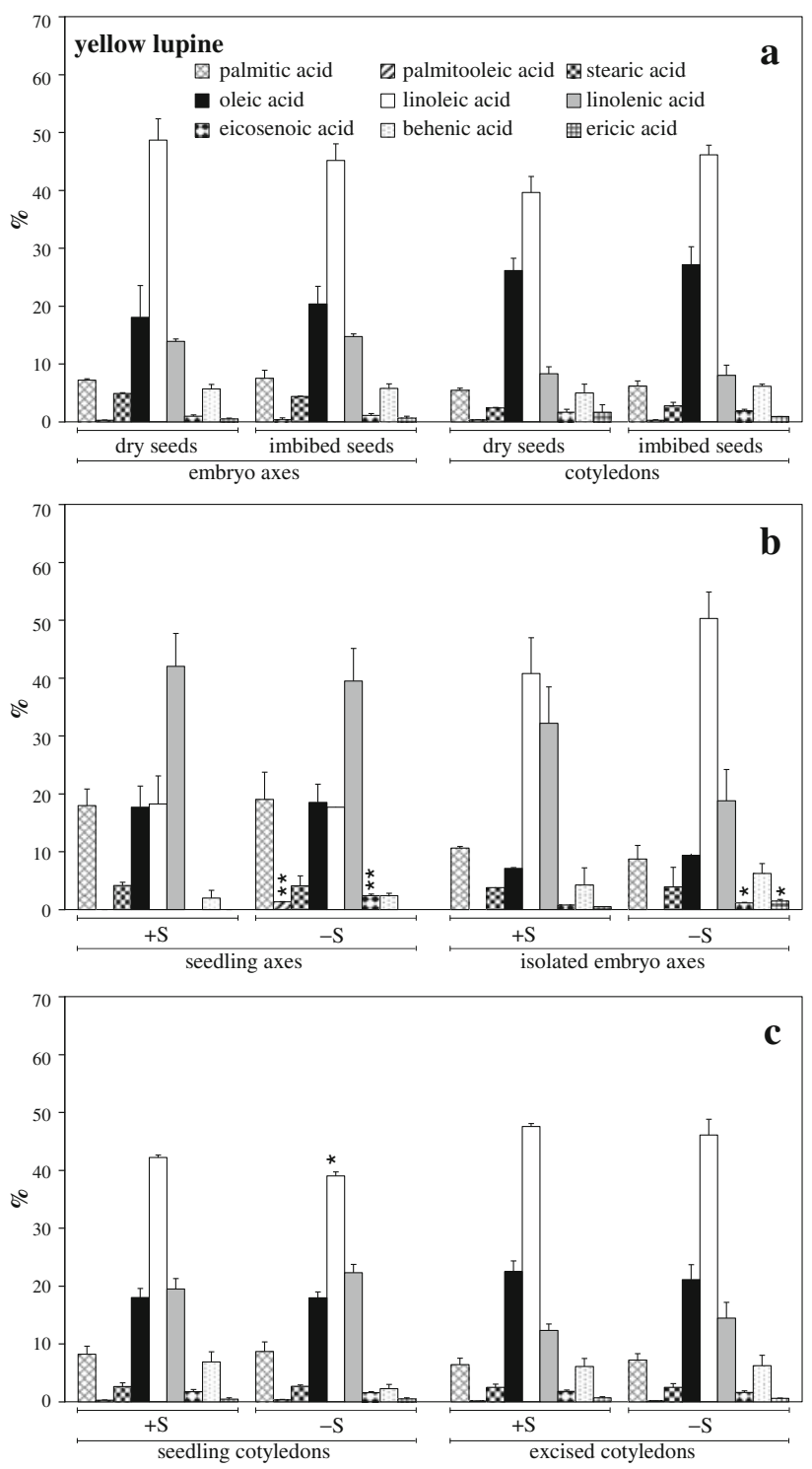

Fig. 2 Fatty acid composition (percentage of total integrated peaks on chromatographs) in yellow lupine embryo axes and cotyledons of dry and imbibed (24 h) seeds (a) and in axes (b) and cotyledons (c) grown in vitro for $96 \mathrm{~h}$ on medium with $60 \mathrm{mM}$ sucrose $(+\mathrm{S})$ or without the sugar $(-\mathrm{S})$. Statistical significance at $P \leq 0.05\left(^{*}\right)$ or at $P \leq 0.01(* *)$

Sucrose added to the medium $(+\mathrm{S})$ caused significant decrease in several phospholipids content, but the most frequent changes were noted in phosphatidylcholine content. In carbohydrate deficiency conditions (-S) phosphatidylcholine content was decreased in yellow, white and Andean lupine seedling axes and in white and Andean isolated embryo axes (Figs. 5b, 6b, 7b). In yellow and white lupine seedling cotyledons and excised cotyledons, no changes or a slight decrease in phosphatidylcholine content was noted and the changes were not statistically significant (Figs. 5c, 6c). The most significant changes in phospholipids content were detected in Andean lupine seedling 

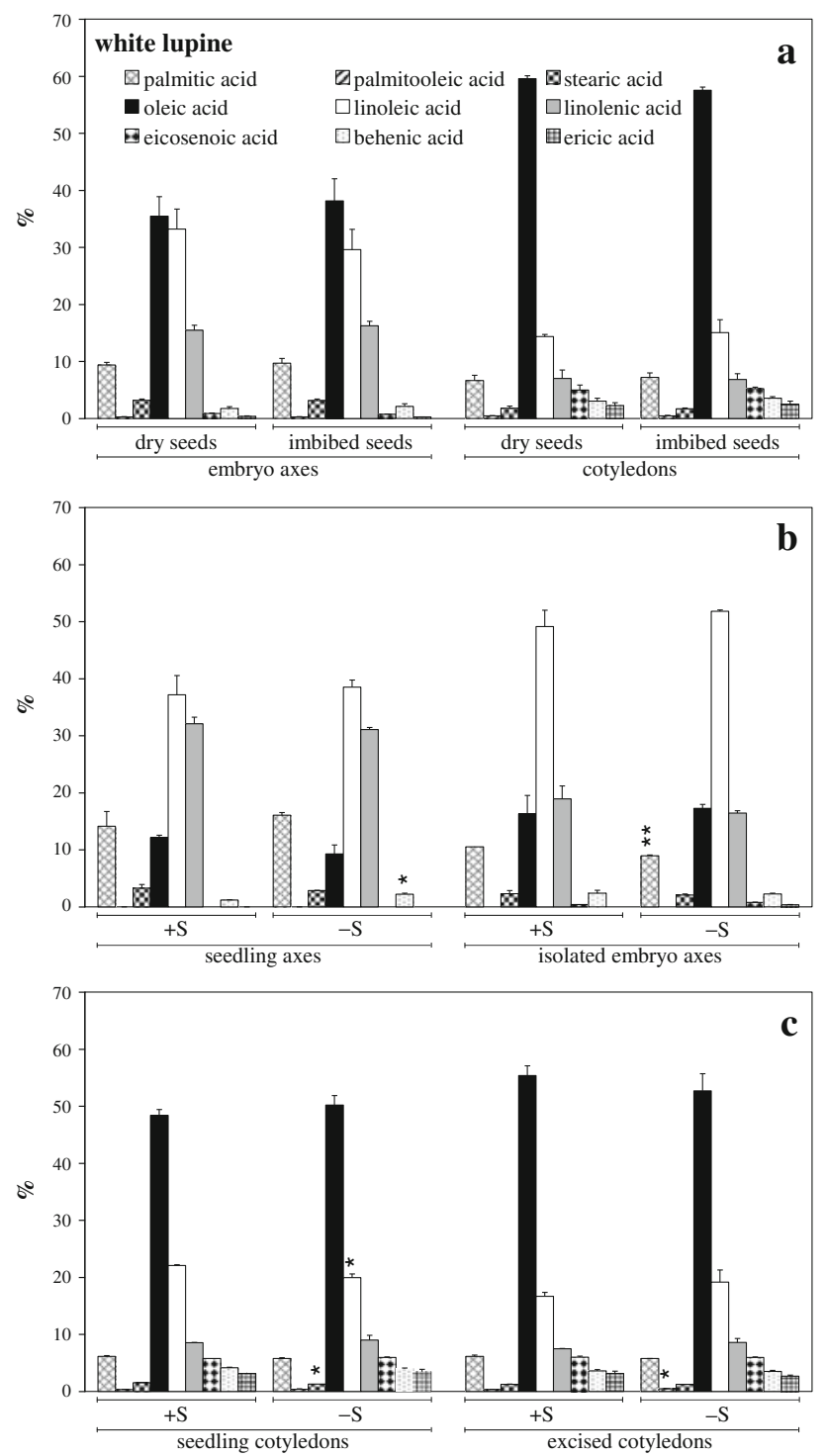

Fig. 3 Fatty acid composition (percentage of total integrated peaks on chromatographs) in white lupine embryo axes and cotyledons of dry and imbibed (24 h) seeds (a) and in axes (b) and cotyledons (c) grown in vitro for $96 \mathrm{~h}$ on medium with $60 \mathrm{mM}$ sucrose $(+\mathrm{S})$ or without the sugar $(-\mathrm{S})$. Statistical significance at $P \leq 0.05(*)$ or at $P \leq 0.01(* *)$

cotyledons and excised cotyledons. In these cotyledons, the content of each phospholipid was lower in sugars depletion conditions in tissues $(-\mathrm{S}$; Fig. 7c).

\section{Discussion}

The regulatory function of sucrose in storage lipid breakdown during lupine seeds germination was investigated. In literature, there are many data, which have proved that in carbohydrate depletion conditions the enhancement of storage compounds mobilization occurs or other cell
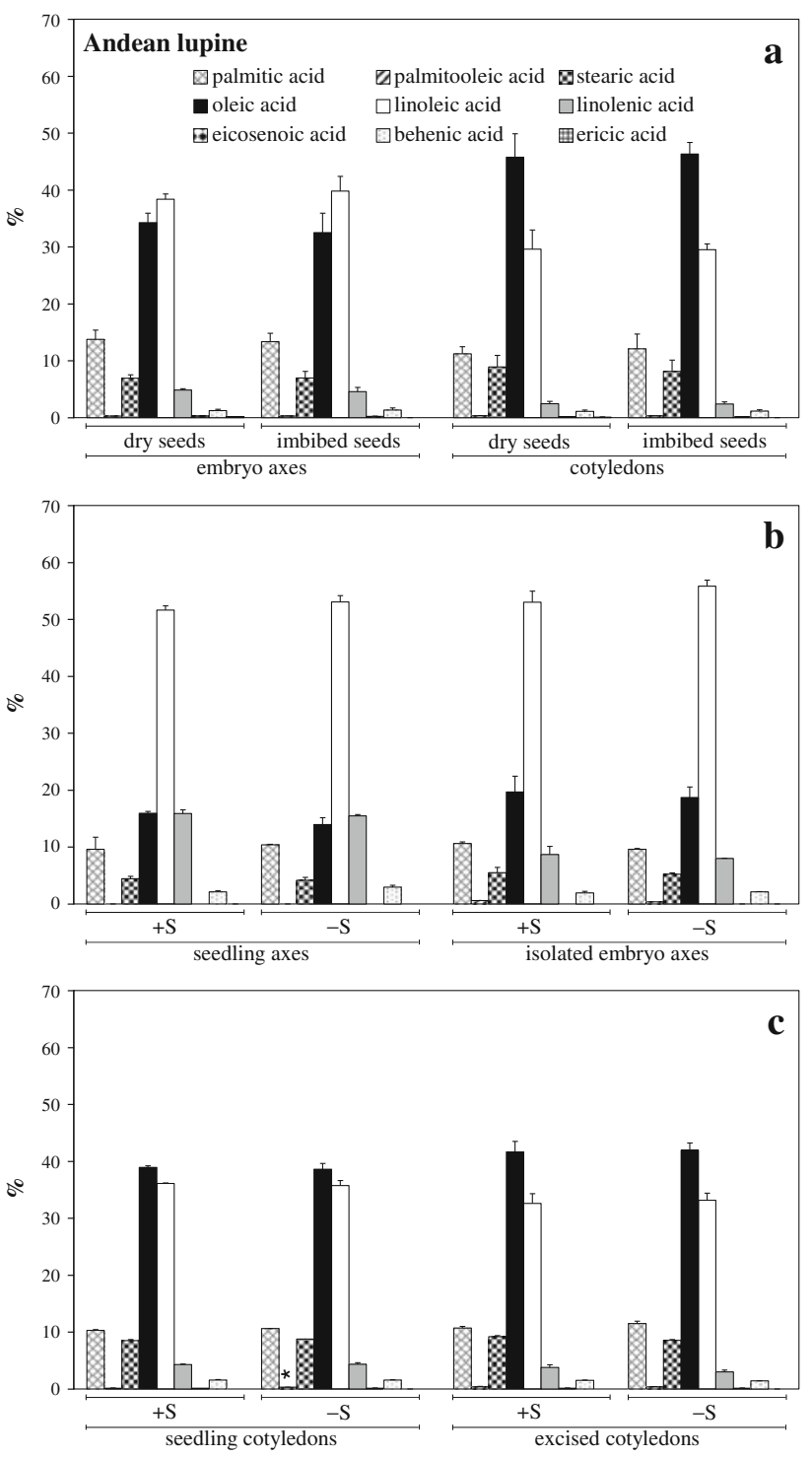

Fig. 4 Fatty acid composition (percentage of total integrated peaks on chromatographs) in Andean lupine embryo axes and cotyledons of dry and imbibed $(24 \mathrm{~h})$ seeds (a) and in axes (b) and cotyledons (c) grown in vitro for $96 \mathrm{~h}$ on medium with $60 \mathrm{mM}$ sucrose $(+\mathrm{S})$ or without the sugar $(-\mathrm{S})$. Statistical significance at $P \leq 0.05(*)$ or at $P \leq 0.01(* *)$

compounds degradation takes place. An example for the regulation by sugars of storage compounds breakdown might be the enhancement of storage protein mobilization in sucrose starved embryo axes and cotyledons during yellow lupine seeds germination (Borek and Ratajczak 2002; Borek et al. 2011a, b) and intensified amino acids utilization as respiratory substrates (Borek et al. 2001; Morkunas et al. 2003). It has been described in details how sugars regulate starch catabolism in germinating cereal seeds (Thomas and Rodriquez 1994). Finally, storage lipid mobilization was retarded by exogenously applied sugars in Arabidopsis (To et al. 2002). 

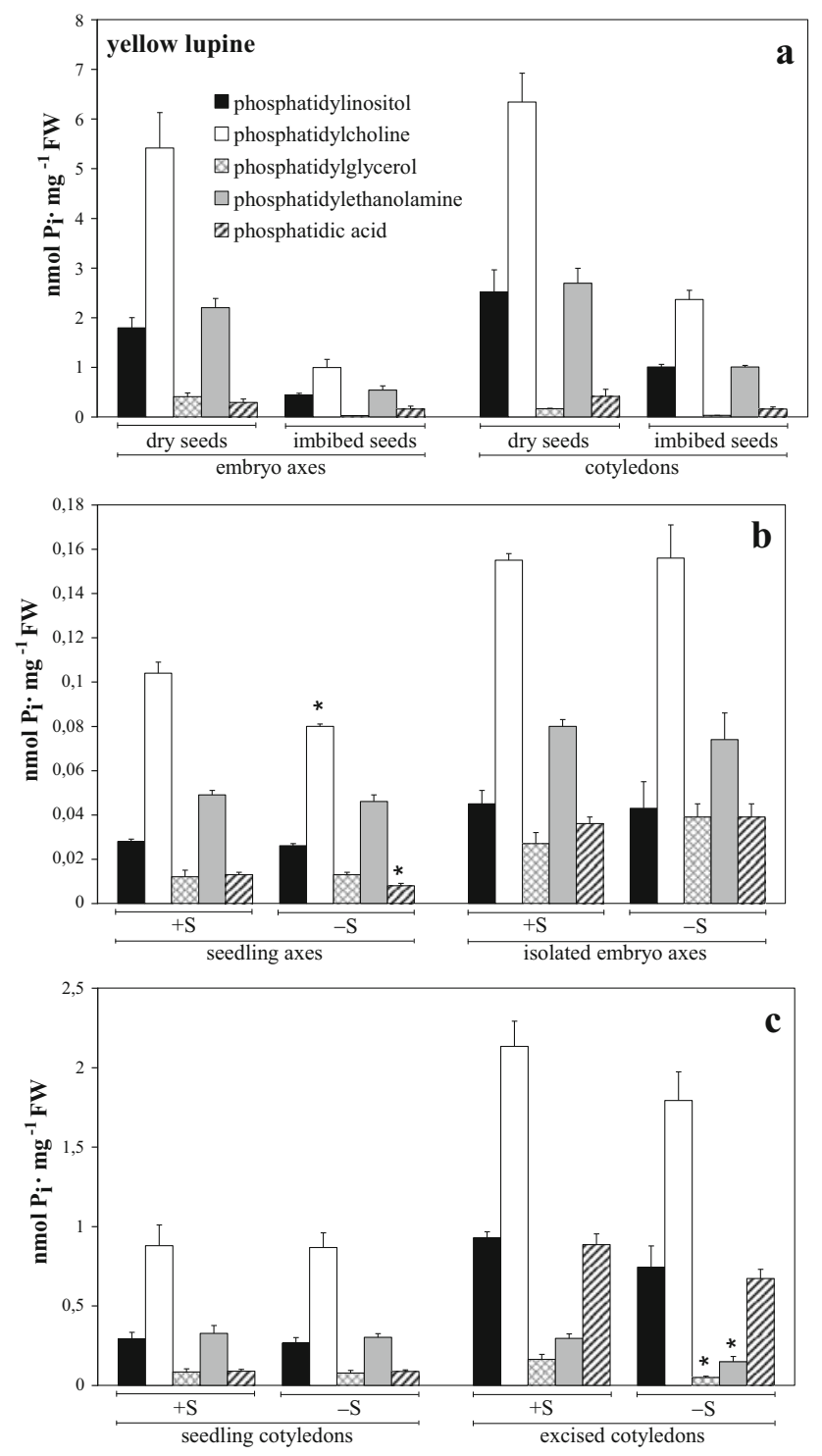

Fig. 5 Phospholipid content in yellow lupine embryo axes and cotyledons of dry and imbibed ( $24 \mathrm{~h})$ seeds (a) and in axes (b) and cotyledons (c) grown in vitro for $96 \mathrm{~h}$ on medium with $60 \mathrm{mM}$ sucrose $(+\mathrm{S})$ or without the sugar $(-\mathrm{S})$. Statistical significance at $P \leq 0.05(*)$

Our previous research on yellow lupine germinating seeds has proved that storage lipid is degraded faster upon sugar-deficient conditions in tissues. Ultrastructure observations have showed that in sucrose-starved embryo axes (exactly in root meristematic zone cells), oil bodies disappear during 96-h germination period while in cotyledons they are smaller and less numerous (Borek et al. 2006, 2011a). Lipase and catalase (enzymes connected with the beginning steps of storage lipid breakdown) activity is also higher in organs grown in vitro on medium without sucrose (Borek et al. 2006). Catalase is associated with the fatty acids $\beta$-oxidation and a rise in its activity can be treated as an indirect proof for intensification of the fatty acids
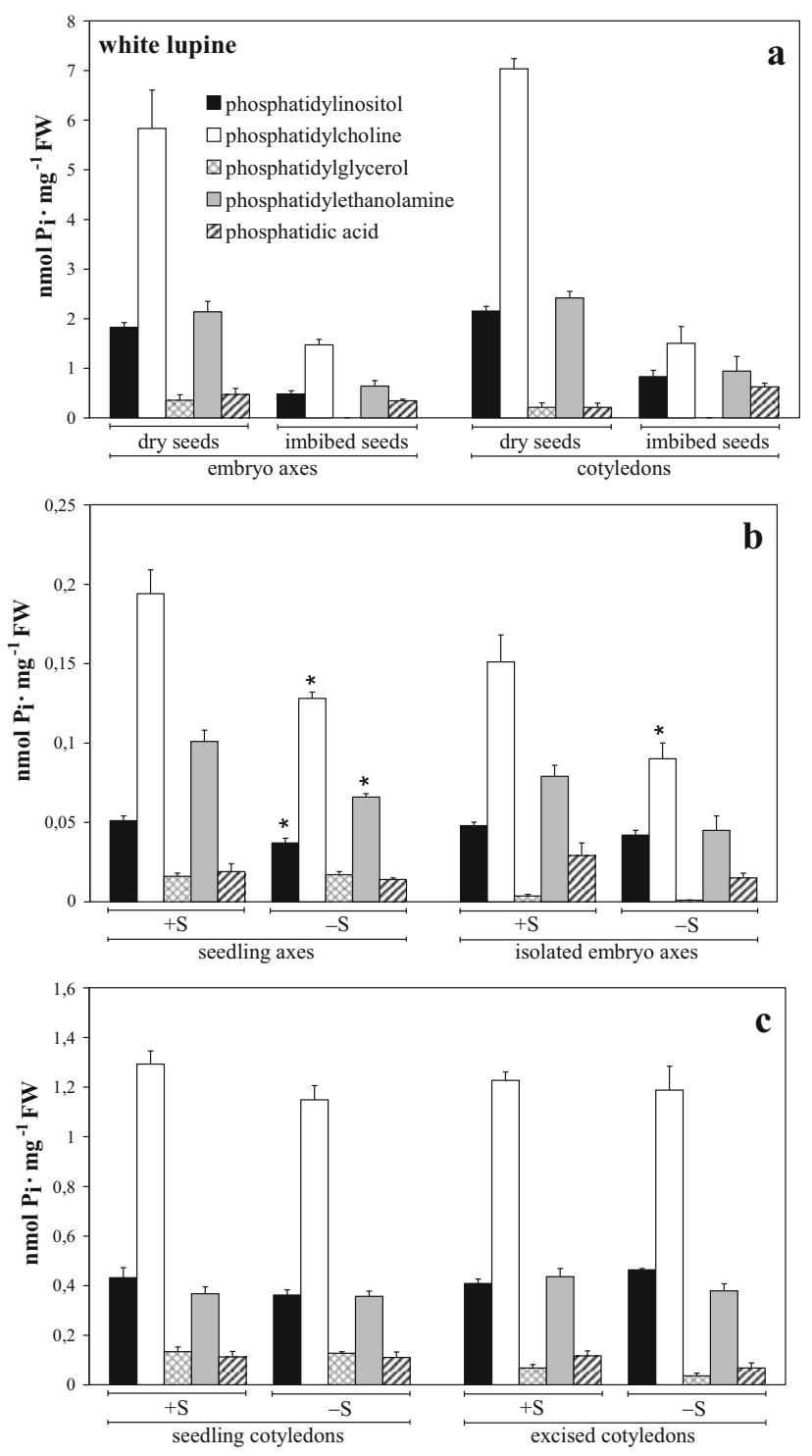

Fig. 6 Phospholipid content in white lupine embryo axes and cotyledons of dry and imbibed ( $24 \mathrm{~h})$ seeds (a) and in axes (b) and cotyledons (c) grown in vitro for $96 \mathrm{~h}$ on medium with $60 \mathrm{mM}$ sucrose $(+S)$ or without the sugar $(-S)$. Statistical significance at $P \leq 0.05(*)$

$\beta$-oxidation in sugar-starved tissues (Dieuaide et al. 1992, 1993). In this paper, the effect of sucrose nutrition on the total lipid level in embryo axes, cotyledons and seedlings of three lupine species is presented. In yellow and white lupine cotyledons, changes caused by sucrose were not significant. Andean lupine cotyledons contained less lipid when they were grown on medium without sucrose $(-S)$. However, in sucrose starved $(-S)$ yellow, white and Andean lupine isolated embryo axes the lipid level was remarkably higher than in axes fed with sucrose $(+S$; Fig. 1). Despite of significant changes caused by sucrose in storage lipid content, there were no numerous changes in fatty acids spectra (Figs. 2b, c, 3b, c, 4b, c). Increase in 

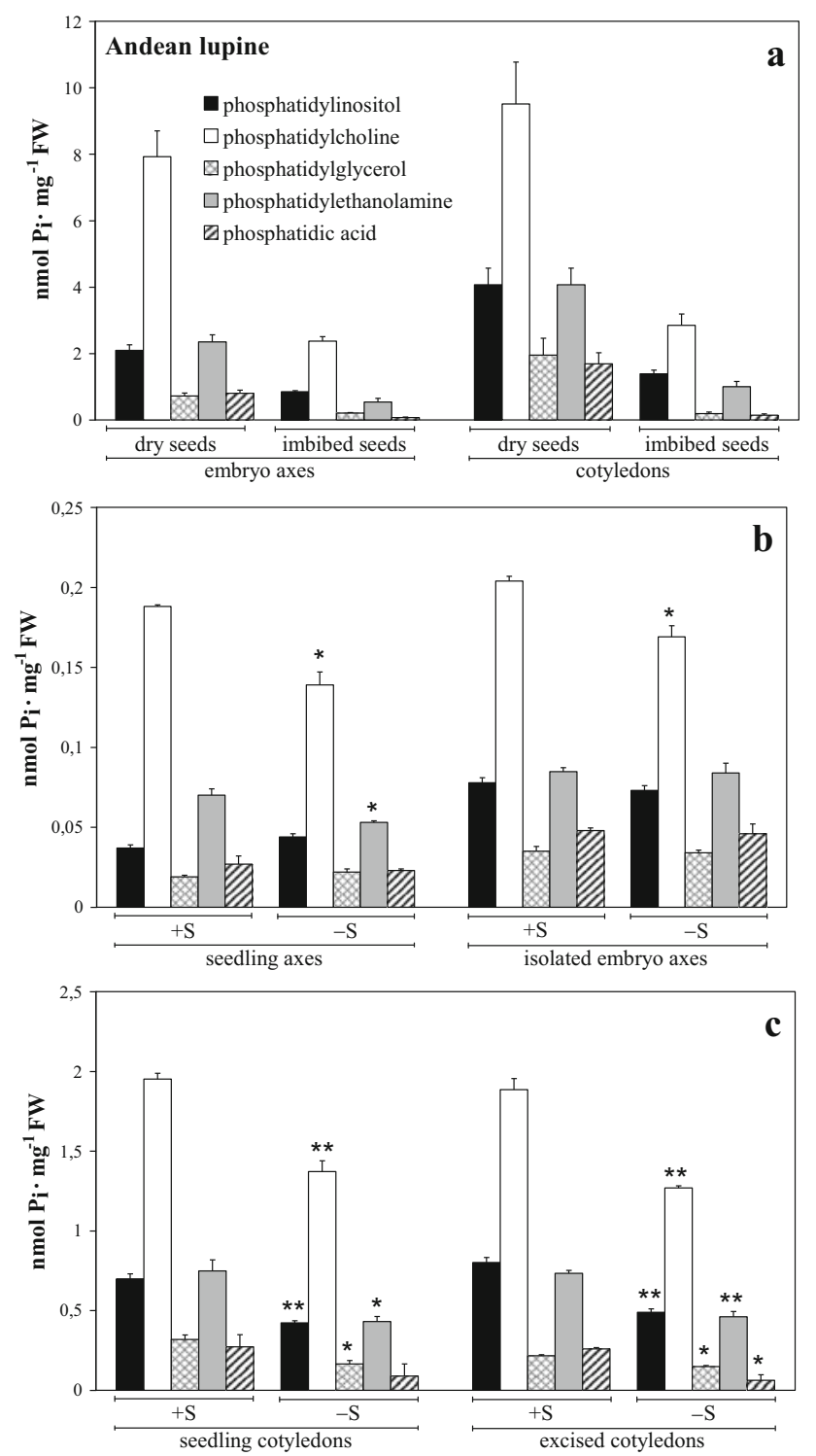

Fig. 7 Phospholipid content in Andean lupine embryo axes and cotyledons of dry and imbibed (24 h) seeds (a) and in axes (b) and cotyledons (c) grown in vitro for $96 \mathrm{~h}$ on medium with $60 \mathrm{mM}$ sucrose $(+\mathrm{S})$ or without the sugar $(-\mathrm{S})$. Statistical significance at $P \leq 0.05(*)$ or at $P \leq 0.01(* *)$

lipid level in $-\mathrm{S}$ isolated embryo axes is consistent with our previously made ultrastructure observations. In white and Andean lupine isolated embryo axes more oil bodies were observed when they were grown on medium without sucrose (-S; Borek et al. 2011a). This result is very difficult to interpret at present stage of the research because it is opposite to other literature data which describe enhanced lipid and fatty acids degradation (Brouquisse et al. 1991; Graham et al. 1994; Yu 1999; To et al. 2002) or increased expression of genes involved in lipid degradation (Graham et al. 1994; Yu 1999; Gonzali et al. 2006; Li et al. 2006) in carbohydrate depletion conditions. Now it is impossible to unambiguously explain the increased lipid content in sucrose-starved lupine isolated embryo axes (Fig. 1). Only suppositions or hypothesis are possible. Maybe such extraordinary higher content of lipid in sucrose starved embryo axes is a result of autophagy? Ultrastructure observations have showed that in sugar-depleted conditions a huge increase in vacuolization occurs in the root meristematic zone cells (Borek et al. 2006, 2011a, b). Enlargement of vacuoles size is one of the effects of autophagy occurring in sugars starved cells (Yu 1999). Maybe peroxisomes (glyoxysomes) or some enzyme proteins involved in lipid breakdown are degraded in this process and since it in sucrose starved $(-\mathrm{S})$ isolated embryo axes remained more lipid. This sequence of events in lupine axes was proposed and described in details in our earlier paper (Borek at al. 2011a). Supposition that in plants might occurred specialized forms of autophagy, which are similar to mentioned above pexophagy was already proposed by Thompson and Vierstra (2005). Data presented in this paper indirectly support the hypothesis. One of result caused by autophagy triggered by carbohydrate starvation is decrease in phospholipid content because of massive membrane lipids degradation (Aubert et al. 1996; Inoue and Moriyasu 2006). In white and Andean lupine $-\mathrm{S}$ isolated embryo axes, a significant decrease in phosphatidylcholine content was observed (Figs. 6b, 7b) even though the lipid level was higher (Fig. 1). The issue discussed above definitely needs additional research, especially on ultrastructure level with the use of concanamycin A and cysteine protease inhibitor E-64 which would allow analyzing the autophagy at remarkably detailed level (Bassham 2007).

Summarizing the data presented in this paper, it can be concluded that carbohydrate level in tissues is a very important agent in regulation of storage lipid breakdown in yellow, white and Andean lupine germinating seeds. Regulation by sucrose of storage lipid mobilization in germinating lupine seeds has some peculiar features. The example for this might be the higher lipid content in sucrose starved isolated embryo axes. This special feature of the regulation of lipid breakdown by sucrose occurred in all three studied lupine species and was independent of storage lipid amount in seeds. A very interesting and needing further research is autophagy induced by carbohydrate depletion in young embryo axes during lupine seeds germination.

Acknowledgments We thank Dr. Stanisław Stawiński, Head of Plant Breeding Station Smolice Division in Przebędowo (Murowana Goślina, Poland), for providing lupine seeds. This work was partially supported by grant no. 2 P06A 00429 from Polish science funding in years 2005-2008.

Open Access This article is distributed under the terms of the Creative Commons Attribution Noncommercial License which permits any noncommercial use, distribution, and reproduction in any medium, provided the original author(s) and source are credited. 


\section{References}

Allen CF, Good P, Davis HF, Chisum P, Fowler SD (1966) Methodology for the separation of plant lipids and application to spinach leaf and chloroplast lamellae. J Am Oil Chem Soc 43:223-230

Ames DN (1966) Assay of inorganic phosphate, total phosphate and phosphatases. Methods Enzymol 8:115-118

Aubert S, Gout E, Bligny R, Marty-Mazars D, Barrieu F, Alabouvette J, Marty F, Douce R (1996) Ultrastructural and biochemical characterization of autophagy in higher plant cells subjected to carbon deprivation: control by the supply of mitochondria with respiratory substrates. J Cell Biol 133:1251-1263

Bassham DC (2007) Plant autophagy-more than a starvation response. Curr Opinion Plant Biol 10:587-593

Baud S, Dubreucq B, Miquel M, Rochat C, Lepiniec L (2008) Storage reserve accumulation in Arabidopsis: metabolic and developmental control of seed filling. The Arabidopsis book. Am Soc Plant Biol. doi:10.1199/tab.0113

Borek S, Morkunas I, Ratajczak W, Ratajczak L (2001) Metabolism of amino acids in germinating yellow lupine seeds III. Breakdown of arginine in sugar-starved organs cultivated in vitro. Acta Physiol Plant 23:141-148

Borek S, Ratajczak W (2002) Sugars as a metabolic regulator of storage protein mobilization in germinating seeds of yellow lupine (Lupinus luteus L.). Acta Physiol Plant 24:425-434

Borek S, Ratajczak W, Ratajczak L (2003) A transfer of carbon atoms from fatty acids to sugars and amino acids in yellow lupine (Lupinus luteus L.) seedlings. J Plant Physiol 160:539-545

Borek S, Ratajczak W, Ratajczak L (2006) Ultrastructural and enzymatic research on the role of sucrose in mobilization of storage lipids in germinating yellow lupine seeds. Plant Sci 170:441-452

Borek S, Pukacka S, Michalski K, Ratajczak L (2009) Lipid and protein accumulation in developing seeds of three lupine species: Lupinus luteus L., Lupinus albus L., and Lupinus mutabilis Sweet. J Exp Bot 60:3453-3466

Borek S, Ratajczak L (2010) Storage lipids as a source of carbon skeletons for asparagine synthesis in germinating seeds of yellow lupine (Lupinus luteus L.). J Plant Physiol 167:717-724

Borek S, Kubala S, Kubala S, Ratajczak L (2011a) Comparative study of storage compound breakdown in germinating seeds of three lupine species. Acta Physiol Plant 33:1953-1968

Borek S, Kubala S, Kubala S (2011b) Regulation by sucrose of storage compounds breakdown in germinating seeds of yellow lupine (Lupinus luteus L.), white lupine (Lupinus albus L.) and Andean lupine (Lupinus mutabilis Sweet). I. Mobilization of storage protein. Acta Physiol Plant. doi:10.1007/s11738-0110870-1

Borek S, Nuc K (2011) Sucrose controls storage lipid breakdown on gene expression level in germinating yellow lupine (Lupinus luteus L.) seeds. J Plant Physiol 168:1795-1803

Brouquisse R, James F, Rajmond P, Pradet A (1991) Study of glucose starvation in excised maize root tips. Plant Physiol 96:619-626

Cerletti P (1982) Lupin seeds proteins. In: Hudson BIF (ed) Development in food proteins. Applied Science Publisher LTD, pp 133-171

Dieuaide M, Brouquisse R, Pradet A, Raymond P (1992) Increased fatty acid $\beta$-oxidation after glucose starvation in maize root tips. Plant Physiol 99:595-600

Dieuaide M, Couée I, Pradet A, Raymond P (1993) Effects of glucose starvation on the oxidation of fatty acids by maize root tip mitochondria and peroxisomes: evidence for mitochondrial fatty acid $\beta$-oxidation and acyl-CoA dehydrogenase activity in higher plant. Biochem J 296:199-207
Duranti M, Consonni A, Magni C, Sessa F, Scarafoni A (2008) The major proteins of lupin seed: characterisation and molecular properties for use as functional and nutraceutical ingredients. Trends Food Sci Tech 19:624-633

Gonzali S, Loreti E, Solfanelli C, Novi G, Alpi A, Perata P (2006) Identification of sugar-modulated genes and evidence for in vivo sugar sensing in Arabidopsis. J Plant Res 119:115-123

Graham IA (2008) Seed storage oil mobilization. Annu Rev Plant Biol 59:115-142

Graham IA, Derby KJ, Leaver CJ (1994) Carbon catabolite repression regulates glyoxylate cycle gene expression in cucumber. Plant Cell 6:761-772

Hedley CL (2001) Grain legume carbohydrates. In: Hedley CL (ed) Carbohydrates in grain legume seeds: improving nutritional quality and agronomic characteristics. CAB International, Wallingford, pp 11-14

Heller R (1954) Recherches sur la nutrition minérale des tissus végétaux ciltivés in vitro. Annu Sci Nat Bot Biol Veg 14:1-223

Inoue Y, Moriyasu Y (2006) Autophagy is not a main contributor to the degradation of phospholipids in tobacco cells cultured under sucrose starvation conditions. Plant Cell Physiol 47:471-480

Li Y, Lee KK, Walsh S, Smith C, Hadingham S, Sorefan K, Cawley G, Bevan MW (2006) Establishing glucose- and ABA-regulated transcription networks in Arabidopsis by microarray analysis and promoter classification using a Relevance Vector Machine. Genome Res 16:414-427

Mohamed AA, Rayas-Duarte P (1995) Composition of Lupinus albus. Cereal Chem 72:643-647

Morkunas I, Garnczarska M, Bednarski W, Ratajczak W, Waplak S (2003) Metabolic and ultrastructural responses of lupine embryo axes to sugar starvation. J Plant Physiol 160:311-319

Nichols BW, Harris RV, James AT (1965) The lipid metabolism of blue-green algae. Biochem Biophys Res Commun 20:256-262

Pukacka S (1991) Changes in membrane lipid components and antioxidant levels during natural ageing of seeds of Acer platanoides. Physiol Plant 82:306-310

Quettier AL, Eastmond PJ (2009) Storage oil hydrolysis during early seedling growth. Plant Physiol Biochem 47:485-490

Ratajczak W, Borek S, Podgórski A, Ratajczak L (1999) Variability of globulin composition in cultivars and individually tested seeds of yellow lupin (Lupinus luteus L.). Acta Physiol Plant 21: 413-417

Santos CN, Ferreira RB, Teixeira AR (1997) Seeds proteins of Lupinus mutabilis. J Agric Food Chem 45:3821-3825

Smeekens S, Jingkun M, Johannes H, Rolland F (2010) Sugar signals and molecular networks controlling plant growth. Curr Opin Plant Biol 13:274-279

Thomas BR, Rodriquez R (1994) Metabolite signal regulate gene expression and source/sink relations in cereal seedlings. Plant Physiol 106:1235-1239

Thompson AR, Vierstra RD (2005) Autophagic recycling: lessons from yeast help define the process in plants. Curr Opin Plant Biol 8:165-173

To JPC, Reiter WD, Gibson SI (2002) Mobilization of seed storage lipid by Arabidopsis seedlings is retarded in the presence of exogenous sugars. BMC Plant Biol 2:4

Weber H, Borisjuk L, Wobus U (2005) Molecular physiology of legume seed development. Annu Rev Plant Biol 56:253-279

Yu SM (1999) Cellular and genetic responses of plants to sugar starvation. Plant Physiol 121:687-693

Zhou S, Zhang D, Luan H, Yu F, Xin X, Hu G (2006) Primary study on protein and lipid accumulation in high oil content soybean varieties. Chin J Oil Crop Sci 28:214-216 